\title{
Conceptual Design of Optimized Fossil Energy Systems with Capture and Sequestration of Carbon Dioxide
}

Semi-Annual Technical Progress Report No. 2

Reporting Start Date: March 23, 2003

Reporting End Date: September 22, 2003

\author{
Principal Author: \\ Dr. Joan M. Ogden \\ ogden@princeton.edu
}

Date Report Issued: December 2003

DOE Award Number: DE-FC26-02NT41623

Address of Submitting Organization:

Princeton Environmental Institute

27 Guyot Hall

Princeton University

Princeton, NJ 08544 


\section{DISCLAIMER}

This report was prepared as an account of work sponsored by an agency of the United States Government. Neither the United States Government nor any agency thereof, nor any of their employees, makes any warranty, express or implied, or assumes any legal liability or responsibility for the accuracy, completeness, or usefulness of any information, apparatus, product, or process disclosed, or represents that its use would not infringe rights. Reference herein to any specific commercial product, process, or service by trade name, trademark, manufacturer, or otherwise does not necessarily constitute or imply its endorsement, recommendation, or favoring by the United States Government or any agency thereof. The views and opinions of authors expressed herein do not necessarily state or reflect those of the United States Government or any agency thereof. 


\title{
Conceptual Design of Optimized Fossil Energy Systems with Capture and Sequestration of Carbon Dioxide
}

\author{
Dr. Joan M. Ogden \\ Elizabeth Kaijuka \\ Wei Wang \\ Princeton Environmental Institute \\ 27 Guyot Hall \\ Princeton University \\ Princeton, NJ 08544
}

\begin{abstract}
In this second semi-annual progress report, we describe research results from an ongoing study of fossil hydrogen energy systems with $\mathrm{CO}_{2}$ sequestration. This work was performed under NETL Award No. DE-FC26-02NT41623, during the six-month period March 2003 through September 2003.

The primary objective of the study is to better understand system design issues and economics for a large-scale fossil energy system co-producing $\mathrm{H}_{2}$ and electricity with $\mathrm{CO}_{2}$ sequestration. This is accomplished by developing analytic and simulation methods for studying the entire system in an integrated way. We examine the relationships among the different parts of a hydrogen energy system, and attempt to identify which variables are the most important in determining both the disposal cost of $\mathrm{CO}_{2}$ and the delivered cost of $\mathrm{H}_{2}$.

A second objective is to examine possible transition strategies from today's energy system toward one based on fossil-derived $\mathrm{H}_{2}$ and electricity with $\mathrm{CO}_{2}$ sequestration. We are carrying out a geographically specific case study of development of a fossil $\mathrm{H}_{2}$ system with $\mathrm{CO}_{2}$ sequestration, for the Midwestern United States, where there is presently substantial coal conversion capacity in place, coal resources are plentiful and potential sequestration sites in deep saline aquifers are widespread.
\end{abstract}




\section{TABLE OF CONTENTS}

\section{EXECUTIVE SUMMARY}

INTRODUCTION

RESULTS AND DISCUSSION

Task 1: Modeling a Fossil Hydrogen Energy System with $\mathrm{CO}_{2}$ Sequestration Task 2: Designing an Optimized Network

Task 3: Case study of Fossil Hydrogen Production in the Midwestern US

CONCLUSIONS

REFERENCES*

BIBLOGRAPHY

LIST OF ACRONYMS AND ABBREVIATIONS

APPENDICES

A. Conversion factors 


\section{LIST OF GRAPHICAL MATERIALS}

\section{FIGURES}

Figure 1. A simple fossil energy system for production of hydrogen and electricity with $\mathrm{CO}_{2}$ sequestration. (variables for the study are shown in italics)

Figure 2. A more complex fossil hydrogen system with $\mathrm{CO} 2$ sequestration.

Figure 3. Method for creating a hydrogen demand map

Figure 4. GIS map showing estimated hydrogen demand in Ohio versus year

Figure 5. Gasoline refueling stations in Columbus, Ohio. Rings show distance from city center in 2 mile increments.

Figure 6. GIS Map of potential CO2 sequestration sites in the US.

Figure 7. Existing infrastructure (clockwise from top left) electric transmission system; coal fired power plants, cng stations, natural gas transmission system; industrial hydrogen production sites, roads and railroads

Figure 8. . GIS data base for Ohio, showing hydrogen demand density; coal fired power plants (red circles); limited access roads and railroads; electric transmission lines, CNG stations.

Figure 9. Hydrogen demand density map for the state of Ohio. Three major urban areas (Cleveland, Columbus and Cincinnati) are highlighted in pink. Areas with more than 200 hydrogen vehicles per $\mathrm{km}^{2}$ are highlighted in blue as potential locations for hydrogen refueling stations. The total hydrogen demand is summed in the highlighted areas using ARCGIS software.

Figure 10. Configuration for centralized hydrogen production with pipeline distribution.

Figure 11. Cost of hydrogen pipeline delivery versus geographic density of hydrogen vehicles.

Figure 12. GIS map of Ohio. Areas with vehicle density of more than 200 vehicles $/ \mathrm{km}^{2}$ are highlighted in blue.

Figure 13. Measurement of distance from General Gavin power plant to city of Columbus along electric transmission right of way using ARCGIS software 
Figure 14. Brine wells and power plants in Ohio.

\section{TABLES}

Table 1. Objective function, constraints and variables for pipeline cost optimization

Table 2. Mathematical programming methods applied to pipeline cost optimization

Table 3. Fraction of hydrogen vehicles in the light duty fleet as a function of market penetration rate and year, for a simple market penetration model where a constant fraction of new vehicles each year are hydrogen-fueled.

Table 4. Ohio Energy Statistics

Table 5. Projected Statewide Hydrogen Use for Vehicles in Ohio and Required Primary Energy Use and $\mathrm{CO}_{2}$ Disposal Capacity

Table 6. Daily H2 Demand in Cities (tonnes/day), assuming a market penetration model where $25 \%$ of new light duty vehicles sold each year use $\mathrm{H} 2$ (the range of values reflects the range of fuel economy projections $40-80 \mathrm{mpg}$ for $\mathrm{H} 2$ vehicles).

Table 7. Hydrogen supply and demand

Table 8. Characteristics of General Gavin electric power plant 


\section{EXECUTIVE SUMMARY}

In this second semi-annual progress report, we describe research results from an ongoing study of fossil hydrogen energy systems with $\mathrm{CO}_{2}$ sequestration. This work was performed during the second six months (March 2003- September 2003) of the project under NETL Award No. DE-FC26-02NT41623.

The primary objective of the study is to better understand system design issues and economics for a large-scale fossil energy system co-producing hydrogen $\left(\mathrm{H}_{2}\right)$ and electricity with carbon dioxide $\left(\mathrm{CO}_{2}\right)$ sequestration. This is accomplished by developing new analytic and simulation tools for studying the entire system in an integrated way. We examine the relationships among the various parts of a fossil hydrogen energy system, and attempt to identify which variables are the most important in determining both the disposal cost of $\mathrm{CO}_{2}$ and the delivered cost of $\mathrm{H}_{2}$.

A second objective is to examine possible transition strategies from today's energy system toward one based on fossil-derived $\mathrm{H}_{2}$ and electricity with $\mathrm{CO}_{2}$ sequestration. We are carrying out a geographically specific case study of development of a fossil $\mathrm{H}_{2}$ system with $\mathrm{CO}_{2}$ sequestration, for the Midwestern United States, where there is presently substantial coal conversion capacity in place, coal resources are plentiful and potential sequestration sites in deep saline aquifers are widespread.

We consider fossil energy complexes producing both $\mathrm{H}_{2}$ and electricity from either natural gas or coal, with sequestration of $\mathrm{CO}_{2}$ in geological formations such as deep saline aquifers. The design and economics of the system depend on a number of parameters that determine the cost and performance of the system "components", as a function of scale and geography (components include: the fossil energy complex, $\mathrm{H}_{2}$ pipelines and refueling stations, $\mathrm{CO}_{2}$ pipelines, $\mathrm{CO}_{2}$ sequestration sites, and $\mathrm{H}_{2}$ energy demand centers). If we know the location, size, cost and performance characteristics of the components, designing the system can be posed as a problem of cost minimization. The goal is to minimize the delivered $\mathrm{H}_{2}$ cost with $\mathrm{CO}_{2}$ disposal by co-optimizing the design of the fossil energy conversion facility and the $\mathrm{CO}_{2}$ disposal and $\mathrm{H}_{2}$ distribution networks. Research to perform this cost minimization has two parts: 1) implement technical and economic models for each "component" in the system, and 2) develop optimization algorithms to size various the system components and connect them via pipelines into the lowest cost network serving a particular energy demand. Finally, to study transition issues, we use these system models to carry out a case study of developing a large-scale fossil energy system in the Midwestern United States.

Three tasks are ongoing. In our first technical progress report, we described work under Tasks 1 and 2. Most of the work described in this report was performed under Tasks 2 and 3. 


\section{Task 1.0 Implement Technical and Economic Models of the System Components}

Here we utilize data and component models of fossil energy complexes with $\mathrm{H}_{2}$ production, and $\mathrm{CO}_{2}$ sequestration already developed or undergoing development as part of the ongoing Carbon Mitigation Initiative (CMI). (Begun in 2001, the Carbon Mitigation Initiative is a ten-year \$15-20 million dollar joint project of Princeton University, BP and Ford Motor Company to find solutions to global warming and climate change.) Additional models for $\mathrm{H}_{2}$ distribution systems and refueling stations are being adapted from the principal investigator's previous studies of $\mathrm{H}_{2}$ infrastructure for the US Department of Energy Hydrogen R\&D Program (Ogden 1998, Ogden 1999a, Ogden 1999b), and those of other researchers (Mintz et al. 2003, Amos 1998, Thomas et al. 1998).

\section{Task 2.0. Integrated Studies of the Entire System to Find the Lowest Cost Network}

As a first step, we developed a simple analytical model linking the components of the system. We consider single fossil energy complex connected to a single $\mathrm{CO}_{2}$ sequestration site and a single $\mathrm{H}_{2}$ demand center. We developed "cost functions" for the $\mathrm{CO}_{2}$ disposal cost and the delivered $\mathrm{H}_{2}$ cost with explicit dependence on the many input parameters described above (e.g. size of demand, fossil energy complex process design, aquifer physical characteristics, distances, pressures etc.). Analytic sensitivity studies of this "simple system" are used to provide us with insights on which parameters are most important in determining costs.

To study more complex and realistic systems involving multiple energy complexes, $\mathrm{H}_{2}$ demand centers, and sequestration sites, we are exploring use mathematical programming methods to find the lowest cost system design. From our system modeling, we seek to distill "rules for thumb" for developing $\mathrm{H}_{2}$ and $\mathrm{CO}_{2}$ infrastructures.

\section{Task 3.0 Case Study of Transition to a Fossil Energy System with $\mathrm{CO}_{2}$ Sequestration}

In this task, the goal is to explore transition strategies: how $\mathrm{H}_{2}$ and $\mathrm{CO}_{2}$ infrastructures might develop in time, in the context of a geographically specific regional case study. We focus on the Midwestern United States, a region where coal is widely used today in coal-fired power plants, and good sites for $\mathrm{CO}_{2}$ sequestration are available. The goal is to identify attractive transition strategies toward a regional hydrogen/electricity energy system in the Midwest with near zero emissions of $\mathrm{CO}_{2}$ and air pollutants to the atmosphere.

To better visualize our results, we use a geographic information system (GIS) format to show the location of $\mathrm{H}_{2}$ demand, fossil energy complexes, coal resources, existing infrastructure (including rights of way), $\mathrm{CO}_{2}$ sequestration sites and the optimal $\mathrm{CO}_{2}$ and $\mathrm{H}_{2}$ pipeline networks. Preliminary results from this task will be described in this report. 


\section{INTRODUCTION}

In this progress report, we present initial results from an ongoing assessment of fossil $\mathrm{H}_{2}$ energy systems with $\mathrm{CO}_{2}$ sequestration. This research was performed during the second six months under NETL Award No. DE-FC26-02NT41623, from March 2003 to September 2003.

\section{Background and Motivation}

Production of hydrogen from fossil sources with capture and sequestration of $\mathrm{CO}_{2}$ offers a route toward near-zero emissions in production and use of fuels. Implementing such an energy system on a large scale would require building two new infrastructures: one for producing and delivering $\mathrm{H}_{2}$ to users (such as vehicles) and one for transmitting $\mathrm{CO}_{2}$ to disposal sites and securely sequestering it.

In Figure 1, we show a fossil hydrogen energy system with $\mathrm{CO}_{2}$ sequestration. A fossil feedstock (natural gas or coal) is input to a fossil energy complex producing hydrogen and electricity. $\mathrm{CO}_{2}$ is captured, compressed to supercritical pressures for pipeline transport to a sequestration site, and injected into an aquifer or other underground geological formation. Hydrogen is delivered to users via a pipeline distribution system that includes compression and storage at the hydrogen production plant, pipelines (possibly with booster compressors) and hydrogen refueling stations. The design and economics of a fossil $\mathrm{H}_{2}$ energy system with $\mathrm{CO}_{2}$ sequestration depend on a host of factors, many of which are regionally specific and change over time. (Variable considered in this study are shown in Figure 1 in italics.) These include:

- The size, type, location, time variation and geographic density of the $\mathrm{H}_{2}$ demands.

- Cost and performance of component technologies making up the system. Key components are: the fossil energy conversion plant [design variables include the scale, feedstock: (coal vs. natural gas), process design, electricity co-production, separation technology, pressures and purity of $\mathrm{H}_{2}$ and $\mathrm{CO}_{2}$ products, sulfur removal options including co-sequestration of sulfur compounds and $\mathrm{CO}_{2}$, location (distance from demand centers and sequestration sites)], $\mathrm{H}_{2}$ and $\mathrm{CO}_{2}$ pipelines and $\mathrm{H}_{2}$ refueling stations.

- The location and characteristics of the $\mathrm{CO}_{2}$ sequestration sites (storage capacity, permeability, reservoir thickness),

- Cost, location and availability of primary resources for $\mathrm{H}_{2}$ production.

- Location of existing energy infrastructure and rights of way (that could be used for siting hydrogen transmission pipelines).

For simplicity, in Figure 1, we have shown a single fossil energy complex, serving a single demand, and one $\mathrm{CO} 2$ sequestration site. However, a future fossil hydrogen system could be more complex, linking multiple $\mathrm{H}_{2}$ demand centers (cities), fossil energy complexes and sites for $\mathrm{CO}_{2}$ sequestration (Figure 2). 
Several detailed technical and economic studies have been carried out for various parts of the system, including $\mathrm{CO}_{2}$ capture from electric power plants (Hendriks 1994; Foster Wheeler 1998; Simbeck 1999), or $\mathrm{H}_{2}$ plants (Foster Wheeler 1996; Doctor et al. 1999; Spath and Amos 1999; Kreutz et al. 2002), $\mathrm{CO}_{2}$ transmission (Skovholt 1993) and storage (Holloway 1996), and $\mathrm{H}_{2}$ infrastructure (Directed Technologies et al. 1997, Ogden 1999; Thomas et al. 1998, Mintz et al 2002). However, relatively little work has been done assessing complete fossil hydrogen systems with $\mathrm{CO} 2$ sequestration in an integrated way. An integrated viewpoint is important for understanding the design and economics of these systems. For example, the scale of the fossil hydrogen plant, can have a large impact on the design and cost of both the hydrogen distribution system, and the system for transporting and sequestering $\mathrm{CO}_{2}$.

\section{Scope of this Study}

The primary objective of this study is to better understand total system design issues and economics for a large-scale fossil energy system co-producing hydrogen $\left(\mathrm{H}_{2}\right)$ and electricity with $\mathrm{CO}_{2}$ sequestration. We consider fossil energy complexes producing both $\mathrm{H}_{2}$ and electricity from either natural gas or coal, with sequestration of $\mathrm{CO}_{2}$ in geological formations such as deep saline aquifers. We apply various analytic and simulation methods to study the entire system in an integrated way. We attempt to identify which variables are the most important in determining both the disposal cost of $\mathrm{CO}_{2}$ and the delivered cost of $\mathrm{H}_{2}$. We examine the relationships among the system components (e.g. fossil energy complexes, $\mathrm{H}_{2}$ and $\mathrm{CO}_{2}$ pipelines, $\mathrm{H}_{2}$ demand centers, and $\mathrm{CO}_{2}$ sequestration sites), and apply new simulation tools to studying these systems, and optimizing their design.

A second objective is to examine possible transition strategies from today's energy system toward one based on fossil-derived $\mathrm{H}_{2}$ and electricity with $\mathrm{CO}_{2}$ sequestration. We focus on understanding how $\mathrm{H}_{2}$ and $\mathrm{CO}_{2}$ infrastructures might evolve over time to meet a growing $\mathrm{H}_{2}$ demand under different regional conditions. If we know the location, size, cost and performance characteristics of the system components, designing the system can be posed as a problem of cost minimization. The goal is to minimize the delivered $\mathrm{H}_{2}$ cost with $\mathrm{CO}_{2}$ disposal by co-optimizing the design of the fossil energy conversion facility and the $\mathrm{CO}_{2}$ and $\mathrm{H}_{2}$ pipeline networks. Research to perform this cost minimization has two parts: 1) implement technical and economic models for each component in the system (Task 1), and 2) explore use of optimization algorithms to size various the system components and connect them via pipelines into the lowest cost network serving a particular energy demand (Task 2). Techniques for studying regional $\mathrm{H}_{2}$ and $\mathrm{CO}_{2}$ infrastructure development and transition strategies are described, based on use of Geographic Information System (GIS) data and network optimization techniques. 
To understand the impact of geographic factors, we are carrying out a case study of development of a large scale fossil $\mathrm{H}_{2}$ system with $\mathrm{CO}_{2}$ sequestration, for the Midwestern United States, where there is presently substantial coal conversion capacity in place, coal resources are plentiful and potential sequestration sites in deep saline aquifers are widespread (Task 3).

Three tasks are ongoing. (Results are given for each task in the "Results and Discussion" section below.) Most of the work described in this report was performed under Tasks 2 and 3. (Results from Task 1 were described in an earlier progress report for this contract (Ogden 2003).

\section{Task 1.0 Implement Technical and Economic Models of the System Components}

Before developing a total system model, we need to develop technical/economic models for the various parts (or components) of the system. Here performance and cost of each "component" of the system is characterized as a function of scale and other relevant parameters. In this Task, we utilize data and models of fossil energy complexes with $\mathrm{H}_{2}$ production, and $\mathrm{CO}_{2}$ sequestration developed as part of the ongoing Carbon Mitigation Initiative (CMI). (Begun in 2001, the Carbon Mitigation Initiative is a tenyear \$15-20 million dollar joint project of Princeton University, BP and Ford Motor Company to find solutions to global warming and climate change.) Additional models for $\mathrm{H}_{2}$ distribution systems and refueling stations are being adapted from the principal investigator's previous studies of $\mathrm{H}_{2}$ infrastructure for the US Department of Energy Hydrogen R\&D Program (Ogden 1998, Ogden 1999a, Ogden 1999b), and those of other researchers (Mintz et al. 2003, Amos 1999, Thomas et al. 1998).

\section{Network}

Task 2.0. Integrated Studies of the Entire System to Find the Lowest Cost

As a first step, we developed a simple analytical model linking the components of the system. We consider a single fossil energy complex connected to a single $\mathrm{CO}_{2}$ sequestration site and a single $\mathrm{H}_{2}$ demand center (see Figure 1). For specificity, we chose a base case hydrogen plant size of 1000 MWth hydrogen output (equivalent to about 600 tonnes $\mathrm{H} 2$ per day or 252 million standard cubic feet - see Appendix A for conversion factors). We developed "cost functions" for the $\mathrm{CO}_{2}$ disposal cost and the delivered $\mathrm{H}_{2}$ cost with explicit dependence on the many input parameters described above (e.g. size of demand, fossil energy complex process design, aquifer physical characteristics, distances, pressures etc.). Analytic sensitivity studies of this "simple system" are used to provide us with insights on which parameters are most important in determining costs.

To study more complex and realistic systems involving multiple energy complexes, $\mathrm{H}_{2}$ demand centers, and sequestration sites, we are exploring use mathematical programming methods to find the lowest cost system design. This work is described under Task 2 below. From our system modeling, we seek to distill "rules for thumb" for developing $\mathrm{H}_{2}$ and $\mathrm{CO}_{2}$ infrastructures. 


\section{Task 3.0 Case Study of Transition to a Fossil Energy System with $\mathrm{CO}_{2}$ Sequestration}

In this task, we explore transition strategies: how $\mathrm{H}_{2}$ and $\mathrm{CO}_{2}$ infrastructures might develop in time, in the context of a geographically specific regional case study. We focus on the Midwestern United States, a region where coal is widely used today in coal-fired power plants, and good sites for $\mathrm{CO}_{2}$ sequestration are available. We consider how fossil energy systems might develop over time to meet an evolving energy demand. The goal is to identify attractive transition strategies toward a regional hydrogen/electricity energy system in the Midwest with near zero emissions of $\mathrm{CO}_{2}$ and air pollutants to the atmosphere.

To better visualize our results, use a geographic information system (GIS) format to show the location of $\mathrm{H}_{2}$ demand, fossil energy complexes, coal resources, existing infrastructure (including rights of way), $\mathrm{CO}_{2}$ sequestration sites and the optimal $\mathrm{CO}_{2}$ and $\mathrm{H}_{2}$ pipeline networks. First, a survey of relevant GIS data sets was conducted, and work was begun on building a database. We used this database to answer simple questions about fossil energy systems with $\mathrm{CO} 2$ sequestration. Results are given below. 


\section{RESULTS AND DISCUSSION}

\section{Task 1.0 Implement Technical And Economic Models Of The System Components}

In the first progress report for this contract, we described technical/economic models of various parts of a fossil hydrogen system with $\mathrm{CO}_{2}$ sequestration. These include:

- The fossil energy complex for producing hydrogen and electricity from natural gas or coal

- $\mathrm{CO}_{2}$ compression and pipeline transport

- $\mathrm{CO}_{2}$ injection into underground geological formations

- Hydrogen demand for vehicles

- Hydrogen fuel delivery infrastructure (including hydrogen compression, storage, pipeline transmission and refueling stations)

We surveyed estimates for system component costs and performance that are available in public domain literature, and from ongoing work at Princeton University. We synthesized cost and performance estimates for hydrogen production systems with $\mathrm{CO}_{2}$ capture, hydrogen pipelines, hydrogen refueling stations, $\mathrm{CO}_{2}$ pipelines, and $\mathrm{CO}_{2}$ injection sites. In particular, we utilized data and component models of fossil energy complexes with $\mathrm{H}_{2}$ production, and $\mathrm{CO}_{2}$ sequestration already developed or undergoing development as part of the ongoing Carbon Mitigation Initiative (CMI) project at Princeton University. Additional models for $\mathrm{H}_{2}$ distribution systems and refueling stations were adapted from the principal investigator's previous studies of $\mathrm{H}_{2}$ infrastructure for the US Department of Energy Hydrogen R\&D Program (Ogden 1998, Ogden 1999a, Ogden 1999b), and those of other researchers (Mintz et al. 2003, Amos 1999, Thomas et al. 1998).

Details on the models for various parts of the system are given in the first progress report for this contract (Ogden 2003). This work will be updated as better estimates become available. For example, the author is working with the "H2A", a group of hydrogen analysts convened by the USDOE to develop cost and performance estimates for hydrogen technologies. The National Research Council is producing a report on hydrogen that will include models of hydrogen components. The results of these efforts should become available in 2004. Our work will be updated to reflect the new information contained in these studies.

Task 2.0. Integrated Studies of the Entire System to Find the Lowest Cost Options 
In Task 2, we combine our "component" models of hydrogen production, $\mathrm{CO}_{2}$ capture, transmission and sequestration, hydrogen compression, storage, distribution and refueling to describe an integrated system.

\section{Task 2.1. Develop Simple Model for Entire System and Perform Sensitivity Studies}

In Task 2.1, we studied total system design and economics, for the special case of a single large fossil energy complex connected to a single geological $\mathrm{CO}_{2}$ sequestration site and a single $\mathrm{H}_{2}$ demand center (such as a city with a large concentration of $\mathrm{H}_{2}$ vehicles). Results for this task were described in the first progress report for this contract. The system is shown in Figure 1. Using the component models from Task 1, we developed a simple analytical model linking the components into a total system. We then estimated the total delivered cost of $\mathrm{H}_{2}$ with $\mathrm{CO}_{2}$ sequestration for a number of cases of interest. We conducted sensitivity studies to examine which parameters are most important in determining delivered hydrogen costs. For our base case assumptions (large $\mathrm{CO}_{2}$ and $\mathrm{H}_{2}$ flows; a relatively nearby reservoir for $\mathrm{CO}_{2}$ sequestration with good injection characteristics; a large, geographically dense $\mathrm{H}_{2}$ demand), $\mathrm{H}_{2}$ production, distribution and refueling were found to be the major costs contributing to the delivered $\mathrm{H}_{2} \operatorname{cost} . \mathrm{CO}_{2}$ capture and sequestration added only $\sim 10 \%$. Better methods of $\mathrm{H}_{2}$ storage would reduce both refueling station and distribution system costs, as well as costs on-board vehicles.

\section{Task 2.2 Explore Use of Mathematical Programming Techniques to Study More Complex Systems.}

Although studies of the simple system in Task 2.1 are useful, a mature fossil hydrogen system would potentially involve a number of hydrogen production sites, hydrogen demand centers, and $\mathrm{CO} 2$ sequestration sites. To study more complex and realistic systems involving multiple energy complexes, $\mathrm{H}_{2}$ demand centers, and sequestration sites, we are exploring use of mathematical programming methods to find the lowest cost system design.

Thusfar, we examined the suitability of several mathematical programming methods that could be used to optimize the design of a hydrogen energy system with $\mathrm{CO} 2$ sequestration More work on Task 2 remains to be done to understand the best tools for carrying out an optimization of the system.

The basic design problem is shown in Figure 2. We have several hydrogen demand centers (shown in yellow) and primary resources. The question is how to connect these using the lowest cost system (including hydrogen production plants, hydrogen distribution and for fossil hydrogen options, a CO2 disposal system.) The longer-term goal is to compare various possible transition pathways to find the lowest overall cost.

This is a complex nonlinear optimization problem. As a first step, we reviewed the literature to understand how mathematical programming techniques had been applied to 
modeling pipeline systems. (This is a subset of the overall design problem, as hydrogen production systems are not specifically included in this analysis.)

Several general classes of problems have been studied, relating to optimizing pipeline systems.

Design Optimization: In this category, we consider the design of a new pipeline network. Since the network doesn't exist yet, we must decide how many compressor stations (if any) are needed, where they should be located, where the interconnection of two (or more) pipes should happen, and what size (diameter and length) each pipe segment should be. Constraints may include mass balance at each node, gas flow equation in every pipe segment, the work equation of compressors and limits on the pressure or flow rate. Infinitely many designs can meet the constraints. The design and building cost is used as the objective function to select one design out of the design space.

Steady-State Operation Optimization: In this case, the network already exists, so pipe size, number and location of compressor stations are already known. The objective is to minimize the fuel consumption by compressors, which is determined by the suction and discharge pressure at each compressor station and the flow-rate of gas going through these compressors.

Table 1 summarizes the objective function (e.g. the cost function to be minimized), the constraints, and the optimization variables. Table 2 shows some of the approaches that have been applied to these two classes of pipeline design problems. Dynamic operation has also been treated, but we do not consider this here, because of its complexity.

\section{Literature Review of Mathematical Programming Methods Applied to Pipeline System Design}

\section{Linear Programming}

In the early years of gas pipeline study, the steady-state operation problem was considered by researchers (Sekirnjak, 1996). They dealt with a very simple network model, consisting of a few sources and sinks. To avoid the nonlinearity caused by the gas flow equation, the network was separated into high, medium and low pressure subsystems, connected by compressors. The pressure drop was neglected within each

\begin{tabular}{|c|c|c|}
\hline & Design Optimization & $\begin{array}{c}\text { Steady-state Operation } \\
\text { optimization }\end{array}$ \\
\hline $\begin{array}{c}\text { Objective } \\
\text { function }\end{array}$ & $\begin{array}{r}\text { building cost } \\
=f(\text { pipe diameter }, \text { pipe length, } \\
\text { \# of compressor }, \text { terrain }, . . .)\end{array}$ & $\begin{array}{c}\text { operation } \cos t(\text { fuel comsumed }) \\
=f(\text { pressure }, \text { flowrate }, . . .)\end{array}$ \\
\hline
\end{tabular}




\begin{tabular}{|c|l|l|}
\hline \multirow{2}{*}{ Constraints } & $\begin{array}{l}\text { 1. mass flow balance equation at } \\
\text { each node } \\
\text { 2. gas flow equation at each pipe } \\
\text { segment, i.e. pressure drop } \\
\text { equation } \\
\text { 3. working equation of each } \\
\text { compressor } \\
\text { 4. limits imposed on pressure or } \\
\text { flow-rate }\end{array}$ & Same as the left \\
\hline $\begin{array}{c}\text { Optimization } \\
\text { variables }\end{array}$ & $\begin{array}{l}\text { pipe diameter and length, location } \\
\text { of compressor stations and other } \\
\text { interconnection points, etc. }\end{array}$ & $\begin{array}{l}\text { flow-rate, suction and } \\
\text { discharge pressure at each } \\
\text { compressor station, etc. }\end{array}$ \\
\hline
\end{tabular}

Table 1. Objective function, constraints and variables for pipeline cost optimization

\begin{tabular}{|c|c|}
\hline $\begin{array}{l}\text { Traditional } \\
\text { optimization } \\
\text { techniques }\end{array}$ & $\begin{array}{l}\text { Pure linear programming } \\
\text { Nonlinear programming } \\
\text { Sequential linear programming (SLP) } \\
\text { General reduced gradient method (GRG) } \\
\text { Inter-point method } \\
\text { Newton-Raphson method } \\
\text { Sequential unconstrained minimization technique (SUMT) } \\
\text { Dynamic programming }\end{array}$ \\
\hline $\begin{array}{l}\text { Nontraditiona } \\
1 \text { optimization } \\
\text { techniques }\end{array}$ & $\begin{array}{l}\text { Genetic algorithms } \\
\text { Simulated annealing } \\
\text { Neural network } \\
\text { Artificial ants }\end{array}$ \\
\hline
\end{tabular}

Table 2. Mathematical programming methods applied to pipeline cost optimization

subsystem, and the only decision variables were the flow-rates through each segment. Thus the network was basically modeled by a set of flow balance equations. This was purely a linear model and then the model could be solved by linear programming techniques. This first optimization application was presented at 12th IGU World Gas Conference in Nice, 1973 (Larcher, et al).

The advantage of LP method is that it has unique optimum, which is the global optimum. The disadvantage is that it can only solve small size network roughly and the 
pressure difference between sources and sinks here must be relatively small so that three subsystems are enough to make the approximation of constant pressure within one subsystem. Otherwise, two possibilities may appear: one is that the computing error becomes too large to tolerate if we keep the same division of three subsystems. The other is to increase the number of subsystems that is essentially a method of linearizing the nonlinear model, which has its own problems of convergence and tolerance.

\section{Non-Linear Programming}

Pipeline system design is an inherently nonlinear problem, so nonlinear programming techniques is a natural tool. Sequential linear programming was used to optimize the steady-state operation of gas pipeline. Edgar (1978) presented a computer algorithm to optimize the design of a gas transmission network. Two solution techniques were used: one was the Generalized Reduced Gradient (GRG) method; the second method was to combine the branch-and-bound scheme with GRG. The techniques were applied to different type of cost functions respectively. Daniel de Wolf (1996) considered the optimal dimensioning of gas transmission network when the net work topology is known. His presented a way to compute the first order derivatives, and used the bundle method (Penalty parameter) for optimization. Siregar (2000) repeated Wolf's work. Djebedjian (2000) applied the sequential unconstrained minimization technique (SUMT) to the operation optimization of hydraulic pipeline system. Benson (2001) took the LOQO nonlinear solver which is based on inner-point method to solve the design problem of small-scale $\mathrm{CO}_{2}$ pipeline network. Both the network topology and the dimension of pipes are unknown variables in her optimization model.

One prominent problem caused by the nonconvexity is how to judge whether the optimum you get is the global optimum. Since most nonlinear optimization techniques are based on iterative methods and the initial value may determines which optimum is found to some extent, changing the initial value may give another solution. Another approach is to find some upper bound for the objective function at pre-processing and use it as one criterion to discard some local optimums (Wu et al. 2000).

\section{Dynamic Programming}

DP has allowed optimization of pressures in steady-state gas pipeline simulations for the past thirty years. This approach allows full used of nonlinear hydraulic models and nonlinear and even discontinuous compressor station models. Any objective function can be used that is a simple sum of costs at each station as a function of flow and inlet/outlet pressures.

The first application on gas pipeline was by Larson and Wong (1968). They applied the method to fuel cost minimization in a single, straight line system and used a recursive formulation, finding the optimal suction and discharge pressures of a fixed number of compressor stations. The length and diameter of the pipeline segments were considered 
fixed because DP was unable to accommodate a large number of decision variables. The first attempt at optimizing a branching structure in the pipeline industry using DP was by Zimmer in 1975. Recent advances have generated a new DP technique, which is called non-sequential (Carter, 1998) or non-serial DP (Bertelè, 1972). Rather than attempting to formulate DP as a recursive algorithm, in this approach we simply look at a system, grab two or three connected compressor or regular elements, and replace them by a "virtual" composite element that behaves just like its components operating in an optimal manner. These elements can be selected from anywhere in the system, so the idea of "recursion" is really not a good description for this process. The process continues, reducing the number of elements in the problem by one each time, until the system can be reduced no further. Typically, that occurs when there is exactly one virtual element left, which completely characterizes the optimal behavior of the entire pipeline network. The best pipeline operation can then be found by just searching one simple table for the lowest occurring value. Using non-sequential dynamic programming allows one to rapidly and exactly solve these problems even with extensive transmission networks involving extensive branching and looping.

\section{Nontraditional Algorithms}

In recent years, a variety of "nontraditional" techniques have been publicized for optimization problems of this sort. Among these methods are Simulated Annealing, Neural Network, Genetic Algorithms and Artificial Ants. The hope is that these methods can give a "more global" optimum. We plan to explore these options further in later work.

\section{Task 2: Future Work}

Studies with a simple analytic model linking one hydrogen production center, one hydrogen demand center and one sequestration site were completed, and papers were presented at conferences. Thusfar, we examined the suitability of several nonlinear programming methods for finding the lowest cost hydrogen system. More work on Task 2 remains to be done to understand the best tools for carrying out an optimization of the system.

\section{Task 3.0 Case Study of Transition to a Fossil Energy System with $\mathrm{CO}_{2}$ Sequestration}

In this task, we explore transition strategies: how $\mathrm{H}_{2}$ and $\mathrm{CO}_{2}$ infrastructures might develop in time, in the context of a geographically specific regional case study. We focus on the Midwestern United States, a region where coal is widely used today in coal-fired power plants, and good sites for $\mathrm{CO}_{2}$ sequestration are available. The goal is to identify attractive transition strategies toward a regional hydrogen/electricity energy 
system in the Midwest with near zero emissions of $\mathrm{CO}_{2}$ and air pollutants to the atmosphere.

In this task, we hope to derive insights about.

- Time constants and costs. How fast can we implement hydrogen fuel infrastructure? How much will it cost? What are the best strategies? What level of demand is needed for widespread implementation of $\mathrm{H}_{2}$ energy system?

- Sensitivities to: technology performance and costs, size and density of demand, local availability of primary sources, characteristics of $\mathrm{CO}_{2}$ sequestration sites, market growth, policies.

- Rules for thumb for optimizing $\mathrm{H}_{2}$ and $\mathrm{CO}_{2}$ infrastructure development.

To better visualize our results, we use a geographic information system (GIS) format to show the location of $\mathrm{H}_{2}$ demand, fossil energy complexes, coal resources, existing infrastructure (including rights of way), $\mathrm{CO}_{2}$ sequestration sites and the optimal $\mathrm{CO}_{2}$ and $\mathrm{H}_{2}$ pipeline networks.

\section{GIS Data for Modeling Fossil Hydrogen Energy Systems with CO2 Sequestration}

As an initial step, a survey of relevant GIS data sets was conducted, and initial work was begun on building a database. The preliminary database includes:

- Population density data, which is used to estimate hydrogen demands

- Data on the existing natural gas system

- Information on the electricity system and power plants

- Information on roads, railroads

- Data on the existing gasoline refueling infrastructure

- Information on sites for $\mathrm{CO}_{2}$ sequestration

We combined this data into a single data base showing features such as hydrogen demand density, location of power plants, etc. This is shown in Figure 8. We use this geographic data as a basis for analyzing alternative configurations for hydrogen supply and $\mathrm{CO}_{2}$ disposal.

\section{Using GIS Data to Model Hydrogen Demand Spatially and Over Time}

Understanding the evolution of a hydrogen fuel delivery infrastructure depends on the spatial and time characteristics of the hydrogen demand. We have developed a simple method to model the magnitude, spatial distribution, and time dependence of hydrogen demand, based on Geographic information system (GIS) data on vehicle populations, and projections for energy use in hydrogen vehicles, and market penetration rates. This method for calculating a hydrogen demand map is described below (see Figure 3). 
- First, population density is mapped as a function of location. This information is available in GIS format from US Census data.

- One average in the US there are about three light duty vehicles for every four people (Davis 2000). From this, we can approximate the numbers of light duty vehicles as a function of location (vehicles $/ \mathrm{km}^{2}$ ). If more detailed information is known about the locations of vehicle fleets, this could be shown as well.

- Next, a market penetration rate for hydrogen is estimated (fraction of new vehicles using hydrogen). This could be done in various ways. For example, one could assume that a "zero emission vehicle mandate" is put in place, so that a fixed fraction of new vehicles sold must use hydrogen. Alternatively, one could devise other criteria for estimating how many new hydrogen vehicles are sold each year, based on projections of when they become competitive with competing technologies like gasoline internal combustion engine technologies. From the market penetration rate, the number of hydrogen vehicles can be found as a function of location and time $\left(\mathrm{H}_{2}\right.$ vehicles $/ \mathrm{km}^{2}$ versus time $)$. Table 3 illustrates how the cumulative fraction of hydrogen vehicles in the light duty fleets grows over time, for a very simple model of market penetration. In this simple "ZEV mandate" model, we assume that a constant fraction of all new cars are hydrogen cars (the ZEV mandate level ranges from $10 \%, 25 \%, 50 \%$, and $100 \%$ ). We also assume that new cars sales are $7 \%$ of the total fleet each year, and that vehicles are replaced after 14 years. We see that the number of hydrogen vehicles grows linearly in time, reaching saturation at about 14 years. Other market penetration scenarios will be examined in future work.

- The hydrogen use per vehicle $\left(\mathrm{kg} \mathrm{H}_{2} / \mathrm{d} /\right.$ vehicle $)$ is estimated from assumptions about hydrogen vehicle fuel economy and miles travelled. A map of hydrogen demand density versus location and time can be calculated $\left(\mathrm{kg} / \mathrm{d} / \mathrm{km}^{2}\right)$. This is shown in Figure 4, for the state of Ohio. The lighter colors are low demand density, the darker colors higher density. The cities of Cleveland, Columbus and Cincinnati are obvious areas of high demand. As time progresses, demand grows, as shown by darkening of the areas around the cities.

Table 3. Fraction of hydrogen vehicles in the light duty fleet as a function of market penetration rate and year, for a simple market penetration model where a constant fraction of new vehicles each year are hydrogen-fueled.

\begin{tabular}{|l|l|l|l|l|}
\hline $\begin{array}{l}\text { H2 Light Duty } \\
\text { Vehicles (fractio } \\
\text { of new LDVs) }\end{array}$ & Year 1 & Year 5 & Year 10 & Year 15 \\
\hline $10 \%$ & $0.7 \%$ & $3.5 \%$ & $7 \%$ & $10 \%$ \\
\hline $25 \%$ & $1.8 \%$ & $9 \%$ & $18 \%$ & $25 \%$ \\
\hline $50 \%$ & $3.5 \%$ & $18 \%$ & $35 \%$ & $50 \%$ \\
\hline $100 \%$ & $7 \%$ & $35 \%$ & $70 \%$ & $100 \%$ \\
\hline
\end{tabular}


Once the hydrogen demand density is known, one has to decide how many refueling stations are required and where they should be sited. The number, location and size of refueling stations have a major effect of the design and cost of infrastructure. This tells us where the hydrogen must be delivered and how much is required. Again, we use GIS data to help guide the process of siting and sizing refueling stations. Let's assume we want future hydrogen stations to be as convenient as today's gasoline stations. In the United States, on average, there is one gasoline refueling station for every 2000 light duty vehicles (Davis 2000), and typical urban stations might serve 3000 light duty vehicles. GIS maps can be used to show where gasoline stations are located. For several cities we examined, stations tend to cluster along major roads in "spoke" or "ring" like patterns. This is shown in Figure 5 for the Columbus, Ohio area. Often, more than one station is found at major intersections or at freeway exits. This suggests that today's convenience level could be preserved, if perhaps $25 \%$ of current gasoline stations offered hydrogen. This is similar to results earlier work that estimated the number of alternative fueled stations needed for customer convenience (Kurani and Sperling 1986; IHIG 2003). For typical US urban vehicle densities of $750-1500 \mathrm{cars} / \mathrm{km}^{2}$, there is one gasoline station per 1.3-4 $\mathrm{km}^{2}$ (assuming each station serves 2000-3000 cars). Equal convenience might be found with one hydrogen station per $5-16 \mathrm{~km}^{2}$. If we know the hydrogen demand per $\mathrm{km}^{2}$, we can find the amount of hydrogen needed at each refueling station as a function of time.

For example, if a fraction $\mathrm{fH} 2$ of all light duty vehicles use hydrogen, each vehicle requires on average $0.7 \mathrm{~kg} \mathrm{H} 2 /$ day, and there are a total of $1500 \mathrm{LDV} / \mathrm{km}^{2}$,

$$
\text { the total } \begin{aligned}
\mathrm{H} 2 \mathrm{demand} / \mathrm{d} / \mathrm{km}^{2} & =\mathrm{fH} 2 \times 1500 \mathrm{LDV} / \mathrm{km}^{2} \times 0.7 \mathrm{~kg} \mathrm{H} 2 / \mathrm{d} / \mathrm{LDV} \\
& =\mathrm{fH} 2 \times 1050 \mathrm{~kg} \mathrm{H} 2 / \mathrm{d} / \mathrm{km}^{2}
\end{aligned}
$$

If we want to preserve the same convenience as today's gasoline stations that each serve a total fleet of 3000 cars, and this level of convenience could be achieved with $25 \%$ of the current gasoline stations,

minimum number of hydrogen stations per $\mathrm{km}^{2}$

$=\left(1500\right.$ gasoline cars $\left./ \mathrm{km}^{2}\right) /(3000$ cars $/$ gasoline station $) \times 25 \%$

$=0.125 \mathrm{H} 2$ stations $/ \mathrm{km}^{2}$

The total of $\mathrm{H} 2$ cars served per station $=\mathrm{fH} 2 \times 3000$ cars $/$ gasoline station $/ 25 \%$

Although the economics of hydrogen refueling stations is better at large size, we might wish to limit the size of the refueling stations to better serve markets. If we assume that the maximum size $\mathrm{H} 2$ station size serves a total fleet of 3000 cars (similar to stations for today's gasoline cars), the demand at this hydrogen station would be $0.7 \mathrm{~kg} \mathrm{H} 2 / \mathrm{car} /$ day x 3000 cars $=2100 \mathrm{~kg} / \mathrm{d} /$ station.)

the total $\mathrm{H} 2$ demand per station $=$ 
$\min \left\{\begin{array}{l}\mathrm{fH} 2 \times(3000 \text { cars } / \text { gaso sta }) / 25 \% \times 0.7 \mathrm{~kg} \mathrm{H} 2 / \mathrm{d} / \mathrm{LDV}=8400 \times \mathrm{fH} 2 \mathrm{~kg} / \mathrm{d} / \mathrm{station} . \\ (3000 \text { cars } / \mathrm{sta}) \times 0.7 \mathrm{~kg} \mathrm{H} 2 / \mathrm{d} / \mathrm{LDV}=2100 \mathrm{~kg} / \mathrm{d} / \mathrm{station}\end{array}\right.$

When $\mathrm{fH} 2>25 \%$, more hydrogen stations would be built rather than increasing the size of the stations. This simple hydrogen demand model and refueling station sizing will be improved in future work.

\section{GIS Data for CO2 Sequestration Sites}

There are several ongoing projects to model the location, characteristics and capacity of $\mathrm{CO} 2$ sequestration sites in the US. A map of possible underground sequestration sites is shown in Figure 6 . This database shows the location of saline aquifers and existing brine wells in the US. The MIDCARB project (MIDCARB project, http://www.midcarb.org) is particularly relevant to our proposed study of fossil hydrogen infrastructure in the Midwestern US. We are investigating how best to incorporate this work into our study. This will be addressed in future progress reports.

\section{GIS Data on Existing Energy Infrastructure and Rights of Way}

We model the availability of resources for hydrogen production and delivery, including the locations of existing infrastructure and rights of way. The location and capacity of existing energy infrastructure and rights of way are an important consideration in developing a hydrogen infrastructure. These include:

- Existing gasoline refueling stations (which give an indication of how transportation fuels are dispensed today, and could be sites for future hydrogen stations).

- Existing hydrogen production plants, storage facilities and pipelines (these might be important for hydrogen supply during the start-up phase of a hydrogen energy system)

- Natural gas transmission and distribution system (hydrogen from natural gas is the lowest cost option in many areas of the US. Hydrogen can be made at a wide range of scales from natural gas.)

- CNG stations (hydrogen stations might be co-located with CNG vehicle fleets)

- Electric power plants (hydrogen might be co-produced at power plants. In many cases, power plants are located near low cost primary resources. These sites might be used for direct production of hydrogen as well.)

- Electric transmission system (electric transmission rights of way might be used by hydrogen pipelines)

- Coal delivery infrastructure (coal might be used to make hydrogen).

- Interstate highways and other limited access roads and railroads. (Rights of way along major roads and railways might be used might be used by hydrogen pipelines.)

GIS databases already exist for many of these systems. As an example, we show the location of electric power transmission lines, coal-fired power plants, CNG stations, the 
natural gas transmission system, existing industrial hydrogen operations and limited access roads and railroads in Ohio (Figure 7). These data have been combined with population density data in Figure 8 to give a composite picture of demand, potential supply and existing infrastructure.

\section{Designing a Regional Hydrogen Infrastructure Using GIS Data: Preliminary Results}

In this section, we present preliminary calculations on designing a regional fossil hydrogen energy system with $\mathrm{CO} 2$ sequestration, utilizing data organized in a GIS database. We have used the state of Ohio, as an example, but these techniques could be used anywhere in the US, where similar GIS data are available.

Some characteristics of the energy system in Ohio are given in Table 4. Ohio is heavily reliant on fossil fuels. About $90 \%$ of the installed electric capacity is coal-fired.

Table 4. Ohio Energy Statistics

\begin{tabular}{|l|l|}
\hline Population & 11.1 people \\
\hline Vehicles & 9.7 million light duty vehicles \\
& 6.7 million cars \\
& 3.0 million light trucks \\
& 3.4 million heavy trucks and buses \\
\hline Light Duty Vehicle Ave. Fuel Economy & $20 \mathrm{mpg}$ gasoline \\
\hline Light Duty Vehicle Ave. Use & 10,250 miles/yr \\
\hline Energy Use & 4300 Trillion BTU/y \\
& $32 \%$ Coal \\
& $20 \%$ Natural Gas \\
& $15 \%$ Gasoline \\
& $7 \%$ Distillate Fuel \\
& $($ other includes fuel oil for heating, nuclear \\
& electricity, biomass $)$ \\
\hline Installed Electric Capacity & 27,000 MWe (2.5 kWe/person) \\
& $90 \%$ coal-fired \\
& $65 \%$ coal plant capacity factor \\
\hline
\end{tabular}

Data Base for Designing Regional Hydrogen Infrastructure

In Figure 8, we have created a GIS database that could be used as a basis for designing a fossil hydrogen energy system with $\mathrm{CO}_{2}$ sequestration for the state of Ohio. Hydrogen demand density $\left(\mathrm{kg} / \mathrm{d} / \mathrm{km}^{2}\right)$ is shown as shading from light colors (low density) 
to darker colors (high density). Superimposed, we have plotted the location of existing coal-fired power plants (circles proportional to the annual electricity production), limited access roads and railroads, existing CNG stations, and the electricity transmission system. Additional information "layers" that could be added include location and capacity of $\mathrm{CO}_{2}$ sequestration sites, the existing natural gas transmission system, and existing industrial hydrogen production system.

\section{Matching Hydrogen Demand and Supply}

In this section we present some simple calculations on matching regional hydrogen supply and demand. First, we look first at statewide demand at different levels of market penetration, and then at particular cities.

In Table 5, we estimate statewide hydrogen energy use in Ohio for light duty vehicles, and estimate the primary resources needed and $\mathrm{CO}_{2}$ disposal system required.

First, we summarize projections for future $\mathrm{H} 2$ light duty vehicle fuel economy and vehicle miles traveled, and estimate the amount of hydrogen energy that would be needed $t$ produce hydrogen for the entire light duty vehicle fleet. It is assumed that future hydrogen vehicles will be 2-4 times as energy efficient as today's gasoline light duty vehicles (e.g. 40-80 miles per gallon gasoline equivalent on an energy basis). Further, we assume that future cars will travel more, so that the projected miles per year grows from today's average value of 10,250 miles to 15,000 miles per year. The energy required is then about 23-47 GJ (1 GJ=10 ${ }^{9}$ joules) per year per hydrogen car, depending on the fuel economy.

For a statewide light duty vehicle population of 9.7 million, the energy use is about 0.21-0.42 Quadrillion BTU/y (or 0.22-0.45 x $10^{18}$ Joules = Exajoules per year). For reference, statewide primary energy use in Ohio today is 4.3 Quadrillion BTU/y, and in the US about 100 Quadrillion BTU/y.

Primary resources needed to make hydrogen are estimated, assuming that all the hydrogen us made from this resource. Producing enough hydrogen for all the light duty vehicles in Ohio would require either:

- $32-64 \%$ increase in current statewide natural gas use or

- $27-54 \%$ increase in current coal use or

- use of all existing off-peak power (assuming that $50 \%$ of the installed capacity could be used off-peak for 12 hours per day), plus an additional 9-44\% dedicated power plant capacity to make hydrogen by electrolysis

Of course, not all hydrogen would necessarily come from one source. Still, this highlights that use of hydrogen in mass vehicle markets would entail a significant use of future primary resources. 
The statewide $\mathrm{CO}_{2}$ disposal capacity needed would total about 35,000-70,000 tonnes/day (13-26 million tonnes/year) if hydrogen transportation fuel is made from natural gas, and 75,000-150,000 tonnes/day (27-55 million tonnes/year), if hydrogen is made from coal. Using $\mathrm{CO}_{2}$ injection wells each capable of handling 2500 tonnes $\mathrm{CO}_{2} /$ day, we would need 14-28 $\mathrm{CO}_{2}$ injection wells if hydrogen is made from natural gas and 30-60, if hydrogen is made from natural gas. Assuming that the $\mathrm{CO}_{2}$ sequestration site is operated for 20 years, we would need a $\mathrm{CO}_{2}$ storage capacity for each well of 18 million tonne $\mathrm{CO}_{2}$, or statewide a sequestration capacity of 0.26-1.1 billion tonnes $\mathrm{CO}_{2}$ to dispose of $\mathrm{CO}_{2}$ from fossil hydrogen transportation fuel production.

Table 5. Projected Statewide Hydrogen Use for Vehicles in Ohio and Required Primary Energy Use and $\mathrm{CO}_{2}$ Disposal Capacity

\section{Projected characteristics of future light duty vehicles}

\begin{tabular}{l|l} 
Fuel Economy (mpg equivalent) for H2 & $2-4 \mathrm{X}$ current gasoline vehicles $=40-80$
\end{tabular}

LDVs mpge

Vehicle use (miles/year) projected for 2050

\begin{tabular}{ll}
\hline Hydrogen use per year $(\mathrm{kg} \mathrm{H} 2 / \mathrm{d} / \mathrm{LDV})$ & $0.52-1.04$
\end{tabular}

\begin{tabular}{ll|l}
\hline Hydrogen energy use per year (GJ/y/LDV) & $23-47$
\end{tabular}

Light Duty Vehicle Populations

Light Duty Vehicles in Ohio (2000)

9.7 million

Hydrogen use statewide

$0.22 \mathrm{EJ} / \mathrm{y}=211$ Trillion BTU

Primary resources required for $\mathrm{H} 2$ production if all $\mathrm{H} 2$ is produced from single source

NG (H2 production via $80 \%$ efficient steam $277-544$ Trillion BTU (32-64\% increase in methane reformer) current NG use)

Coal (H2 production via 60\% efficient $369-739$ Trillion BTU (27-54\% increase in gasifier) current coal use)

Electricity (H2 via 80\% efficient electrolysis If all existing off-peak power (assumed to b $50 \%$ of $27,000 \mathrm{MWe}$ current installed capacity, available for $12 \mathrm{~h} / \mathrm{d}$ ) is used, additional dedicated power plants for electrolytic $\mathrm{H} 2$ production $=9-44 \% \times$ (the existing electric capacity) would be needed.

\section{$\mathrm{CO}_{2}$ Disposal capacity needed} Coal-> $\mathrm{H} 2$ plant

$75,000-150,000$ tonnes $\mathrm{CO}_{2} / \mathrm{d}$

30-60 $\mathrm{CO}_{2}$ wells@2500 tonnes/d/well

0.6-1.1 billion tonnes $\mathrm{CO}_{2}$ over 20 years 


$$
\mathrm{NG}->\mathrm{H} 2 \text { plant }
$$

35,000-70,000 tonnes $\mathrm{CO}_{2} / \mathrm{d}$

Matching citywide demand for hydrogen with supply

In Figure 9, we map the hydrogen demand density in the state of Ohio, highlighting the three largest urban areas in Ohio: Cincinnati, Columbus and Cleveland, which are shown in pink. In addition, we have highlighted in blue areas with a vehicle density of more than 200 hydrogen cars per $\mathrm{km}^{2}$, as likely sites for hydrogen refueling stations, and possibly distribution pipelines.

Using tools in the GIS program ARCGIS, it is easy to select geographic areas for analysis. Regions near each of the three urban areas are highlighted. We then sum up the hydrogen demand over for each city. In Table 6, we calculate hydrogen demand in three cities and statewide, over time, assuming that starting in year $1,25 \%$ of new vehicles sold each year use hydrogen.

Table 6. Daily H2 Demand in Cities (tonnes/day), assuming a market penetration model where $25 \%$ of new light duty vehicles sold each year use $\mathrm{H} 2$ (the range of values reflects the range of fuel economy projections $40-80 \mathrm{mpg}$ for $\mathrm{H} 2$ vehicles).

\begin{tabular}{|l|l|l|l|l|}
\hline & Year 1 & Year 5 & Year 10 & Year 15 \\
\hline $\begin{array}{l}\text { Fraction of H2 } \\
\text { cars in fleet }\end{array}$ & $1.8 \%$ & $9 \%$ & $18 \%$ & $25 \%$ \\
\hline City & Hydrogen demand (tonnes/ H2/day) \\
\hline Cleveland & $6-12$ & $30-60$ & $60-120$ & $84-168$ \\
\hline Columbus & $4-9$ & $22-44$ & $44-88$ & $62-123$ \\
\hline Cincinnati & $5-9$ & $23-46$ & $46-92$ & $64-129$ \\
\hline Statewide & $38-77$ & $192-384$ & $384-768$ & $538-1076$ \\
\hline
\end{tabular}

We now contrast the projected hydrogen demand to the size of various hydrogen supply options shown in Table 7. Large coal gasification plants produce 150-600 tonnes of hydrogen per day, while steam methane reformers are more typically in the range 48-480 tonnes hydrogen per day. This suggests that at the levels of hydrogen demand found at year 10 (18\% of light duty vehicles use H2), a steam reformer is a better match in size to the city demand than a dedicated coal gasification plant. One large coal to hydrogen plant could provide hydrogen for the entire state, but this would require an extensive long distance hydrogen transmission system (by pipeline or truck).

If higher market penetration of hydrogen cars (for example, if $100 \%$ of light duty vehicles used hydrogen), a single city might require enough hydrogen for a dedicated coal plant.

Hydrogen distribution within a city 
We can also use the GIS database to look at hydrogen distribution options within a city. In particular, we ask the question "when does local pipeline distribution of hydrogen make sense?" We assume that the hydrogen infrastructure includes a central $\mathrm{H} 2$ production plant with small distribution pipelines serving refueling stations, configured in radial spokes (Figure 10). In Figure 11, we plot the cost of hydrogen pipeline distribution versus the 
Table 7. Hydrogen Supply and Demand

\begin{tabular}{|c|c|c|c|}
\hline $\mathrm{H}_{2}$ Demands & $\mathrm{kg} \mathrm{H}_{2} /$ day & & \\
\hline $\begin{array}{l}1 \mathrm{H}_{2} \mathrm{FC} \text { car } \\
(82 \mathrm{mpg}, 11,000 \mathrm{mi} / \mathrm{y})\end{array}$ & 0.375 & & \\
\hline $\begin{array}{l}1 \mathrm{H}_{2} \mathrm{FC} \mathrm{Bus} \\
(7 \mathrm{mpge}, 50,000 \mathrm{mi} / \mathrm{y})\end{array}$ & 20 & & \\
\hline $\begin{array}{l}100-1000 \mathrm{H}_{2} \mathrm{FC} \mathrm{car} \\
\text { fleet cars } \\
(82 \mathrm{mpg}, 17,000 \mathrm{mi} / \mathrm{y})\end{array}$ & $58-580$ & & \\
\hline $100-1000$ FC Buses & $2000-20,000$ & & \\
\hline $\begin{array}{l}100,000 \text { cars }(\sim 1 \% \text { of } \\
\text { cars in } L A)\end{array}$ & $\mathbf{3 7 , 5 0 0}$ & & \\
\hline $\begin{array}{l}1 \text { million cars } \\
(\sim 10 \% \text { of cars in LA })\end{array}$ & 375,000 & & \\
\hline $\begin{array}{l}10 \text { million cars } \\
(\sim 100 \% \text { cars in LA })\end{array}$ & $3,750,000$ & & \\
\hline $\mathrm{H}_{2}$ Supplies & $\mathrm{kg} \mathrm{H}_{2} /$ day & $\begin{array}{c}\text { Size of } \mathrm{H}_{2} \text { FC car fleet } \\
\text { supported }\end{array}$ & $\begin{array}{c}\text { Size of } \mathrm{H}_{2} \mathrm{FC} \mathrm{Bus} \\
\text { fleet }\end{array}$ \\
\hline $\begin{array}{c}\text { Compressed } \mathrm{H}_{2} \text { gas truck } \\
\text { (1/day) }\end{array}$ & 420 & 1120 & 21 \\
\hline Liquid H2 truck (1/day) & 3600 & 9600 & 180 \\
\hline Onsite electrolyzer & $2.4-2400$ & $6.4-6400$ & $0.12-120$ \\
\hline $\begin{array}{l}\text { Onsite steam methane } \\
\text { reformer (SMR) }\end{array}$ & $240-4800$ & $640-12,800$ & $12-240$ \\
\hline $\begin{array}{l}\text { Industrial scale steam } \\
\text { methane reformer }\end{array}$ & $\begin{array}{l}48,000- \\
480,000\end{array}$ & $128,000-1,280,000$ & $2400-24,000$ \\
\hline $\begin{array}{l}\text { Coal gasifier } \mathrm{H}_{2} \text { plant } \\
\text { w/CO } \mathrm{C}_{2} \text { seq. }\end{array}$ & $\begin{array}{l}150,000- \\
600,000\end{array}$ & $400,000-1,600,00$ & $7500-30,000$ \\
\hline $\begin{array}{l}\mathrm{H}_{2} \text { from } 10 \% \text { of } \mathrm{NG} \\
\text { Flow into LA }\end{array}$ & $1,700,000$ & $4,533,333$ & 85,000 \\
\hline $\begin{array}{l}\mathrm{H}_{2} \text { from } 1000 \mathrm{MW} \\
\text { off-peak power }\end{array}$ & 240,000 & 640,000 & 12,000 \\
\hline
\end{tabular}


geographic density of vehicles. We see that pipeline distribution costs rise rapidly at geographic densities of less than about 200 vehicles $/ \mathrm{km}^{2}$. (At these lower vehicle densities, onsite production of hydrogen or truck delivery are less costly than pipelines (Ogden 1999)). In Figure 12, we highlight all the areas in the state where the density of vehicles exceeds $200 / \mathrm{km} 2$. In the limit of $100 \%$ hydrogen vehicle use, these areas would be possible sites for hydrogen distribution pipelines. We use the GIS database to sum the population in all the highlighted areas. We find that about $70 \%$ of people live in areas of high vehicle density that are long term possibilities for pipeline distribution. This suggests that many consumers ( $30 \%$ for this set of assumptions) live in areas where local pipelines will always be a costly mode of bringing hydrogen to refueling stations, even if all the vehicles run on hydrogen.

\section{GIS-aided design of a system for supplying hydrogen to Columbus from coal-based hydrogen plants with $\mathrm{CO}_{2}$ sequestration}

As an example, we consider the design and cost of a system supplying hydrogen to the city of Columbus from a coal to hydrogen plant with $\mathrm{CO}_{2}$ sequestration. Columbus has a population of about 1 million, with about 700,000 light duty vehicles. Assuming that future hydrogen vehicles have a fuel economy between 2-4X that of today's gasoline cars, and that future vehicles travel more (15,000 miles/year versus 10,250 today) the average hydrogen use per car is $0.5-1.0 \mathrm{~kg} / \mathrm{d} / \mathrm{car}$. The total hydrogen demand for all light duty vehicles in the city would be 350-700 tonnes $\mathrm{H} 2$ per day. (We have not assumed growth in population. If this were included, the hydrogen demand in the future would be greater.)

We now examine possible sites for producing hydrogen for Columbus from coal. From our GIS database (Figure 8), we see several red circles representing coal fired power plants located near Columbus. "Clicking" on various power plant sites, we find that the nearest large coal-fired power plant is the "General Gavin" plant, located along the Ohio river. From the GIS database, the characteristics of this plant are readily available (see Table 8).

From examining the map in Figure 8, we see that there are a number of potential rights of way that might be used to connect the General Gavin plant to the city of Columbus via pipelines. These include electric transmission rights of way (which are ideal, since they run from power plants to cities), railway rights of way and limited access highways. Using an ARCGIS measuring software tool (Figure 13), we find that the distance from the General Gavin plant to downtown Columbus, measured along an electric transmission right of way is $150 \mathrm{~km}$.

Table. 8. Characteristics of General Gavin Electric Power Plant

Year Built 1974 


\begin{tabular}{|l|l|}
\hline Type & $\begin{array}{l}\text { Pulverized Coal Steam plant with flue gas } \\
\text { desulfurization, low NOx burners, SCR }\end{array}$ \\
\hline Nameplate capacity (MW) & 2600 \\
\hline Electricity production (MWh/y) & 17 million \\
\hline Ave. capacity factor & $74 \%$ \\
\hline Coal Consumption (million tonnes/year) & 7.2 \\
\hline Coal delivery & $100 \%$ by barge \\
\hline Plant Energy Efficiency (kWhe/kWh coal) & $30 \%$ \\
\hline $\begin{array}{r}\text { CO2 production (tonne/day) } \\
\text { (million tonne/y) }\end{array}$ & 50,000 \\
& 18.6 \\
\hline
\end{tabular}

Assuming that hydrogen could be produced from coal at $65 \%$ conversion efficiency, about $18-36 \%$ of the current coal consumed at the General Gavin plant would be needed to produce hydrogen for vehicles in Columbus. The General Gavin power plant is operated at only $\sim 74 \%$ capacity factor today, because it follows electricity load. If this plant is "repowered" with a coal IGCC, with $\mathrm{CO}_{2}$ capture, and run at a higher efficiency and higher capacity factor, then it might be possible to supply electric needs and make enough $\mathrm{H}_{2}$ during off-peak electric demand hours for light duty vehicles. (This idea will be analyzed in later work.)

A pipeline bringing hydrogen $150 \mathrm{~km}$ from the General Gavin plant to the city would add a relatively small amount to the delivered cost of $\mathrm{H}_{2},<\$ 1 / \mathrm{GJ}$. $\mathrm{H}_{2}$ storage at the central plant might add another $\$ 1.5 /$ GJ. Distribution and refueling would add another $\$ 8-10 /$ GJ (Ogden 2003).

$\mathrm{A} \mathrm{CO}_{2}$ disposal system for the fossil energy plant (assuming the same coal consumption as today) would require about 20 injection wells, assuming that each well handled 2500 tonnes $\mathrm{CO}_{2}$ per day. Most coal consumption would be associated with electricity production. The ratio of electric energy demand to $\mathrm{H}_{2}$ energy demand for LDVs is about 8:3 (4:3) for $\mathrm{H}_{2}$ vehicles with $4 \mathrm{X}(2 \mathrm{X})$ current gasoline fuel economy.

Possible sites for $\mathrm{CO}_{2}$ sequestration are being evaluated as part of various ongoing studies such as the MIDCARB project. We will be using this data in future work. As an example, we show a map of power plants and existing brine wells in Ohio in Figure 14. If these represented $\mathrm{CO}_{2}$ sequestration sites, we could estimate the distance from the fossil energy complex using GIS measuring tools, and find pipeline distances and costs. For a $\mathrm{CO}_{2}$ flow rate of 50,000 tonnes/day, the levelized cost of $\mathrm{CO}_{2}$ pipeline transmission a $100-200 \mathrm{~km}$ and injection should be a small addition to the total hydrogen cost (Ogden, Kaijuka and Wang 2003).

\section{Task 3: Future work}


We have developed a GIS data base showing potential demand for hydrogen, location of existing infrastructure, including current coal-fired power plants and major road and railroads (which are potential rights of way for hydrogen or $\mathrm{CO} 2$ pipelines) and possible sites for $\mathrm{CO} 2$ sequestration. Preliminary results have been presented at two conferences in 2003. We have not yet estimated costs for alternative pathways for developing fossil hydrogen as an energy carrier, or coordinated with other ongoing GIS based studies of CO2 sequestration potential such as the MIDCARB project.

\section{CONCLUSION}

During the second six months of research under this contract, we have made significant progress toward understanding the systems aspects of fossil hydrogen systems with $\mathrm{CO} 2$ sequestration, and meeting our objectives for the overall project. Below, we summarize by Task the current status of the project and plans for future work.

\section{Task 1.0 Implement Technical and Economic Models of the System Components}

Description: Here we utilize data and component models of fossil energy complexes with $\mathrm{H}_{2}$ production, $\mathrm{H}_{2}$ distribution systems and refueling stations and $\mathrm{CO}_{2}$ sequestration being developed as part of earlier work at Princeton and other efforts.

Status: We have surveyed estimates for system component costs and performance that are available in public domain literature, and from ongoing work at Princeton. We have synthesized cost and performance estimates for hydrogen production systems with $\mathrm{CO} 2$ capture, hydrogen pipelines, hydrogen refueling stations, $\mathrm{CO} 2$ pipelines, and $\mathrm{CO} 2$ injection sites. This work was described in the first progress report.

Future Work: Over the next year, we plan to improve these cost and performance estimates. In particular, the principal investigator Joan Ogden has been involved with the H2A group, an ongoing effort at the USDOE, which brings together analysts (funded under various DOE programs) who study hydrogen systems. This group has been reviewing the costs and performance of hydrogen production, delivery and refueling systems. Access to these data will give improved estimates of components costs and performance under Task 1. The National Research Council is producing a report on hydrogen that will include models of hydrogen components. The results of these efforts should become available in 2004. In addition, the PI will check with the latest results from modeling efforts under the CMI project at Princeton. Our work will be updated to reflect the new information contained in these studies.

\section{Task 2.0. Integrated Studies of the Entire System to Find the Lowest Cost Network}

Description: As a first step, we developed a simple analytical model linking the components of the system. We considered single fossil energy complex connected to a 
single $\mathrm{CO}_{2}$ sequestration site and a single $\mathrm{H}_{2}$ demand center. To study more complex and realistic systems involving multiple energy complexes, $\mathrm{H}_{2}$ demand centers, and sequestration sites, we are exploring use mathematical programming methods to find the lowest cost system design.

Status: Studies with a simple analytic model linking one hydrogen production center, one hydrogen demand center and one sequestration site were completed, and papers were presented at conferences. We have looked at several nonlinear programming approaches to modeling $\mathrm{CO}_{2}$ pipeline disposal systems.

Future Work: More work on Task 2 remains to be done to understand the best tools for carrying out an optimization of the system.

\section{Task 3.0 Case Study of Transition to a Fossil Energy System with $\mathrm{CO}_{2}$ Sequestration}

Description: In this task, we explore transition strategies: how $\mathrm{H}_{2}$ and $\mathrm{CO}_{2}$ infrastructures might develop in time, in the context of a geographically specific regional case study. We focus on the Midwestern United States, a region where coal is widely used today in coalfired power plants, and good sites for $\mathrm{CO}_{2}$ sequestration are available. To better visualize our results, we use a geographic information system (GIS) format to show the location of $\mathrm{H}_{2}$ demand, fossil energy complexes, coal resources, existing infrastructure (including rights of way), $\mathrm{CO}_{2}$ sequestration sites and the optimal $\mathrm{CO}_{2}$ and $\mathrm{H}_{2}$ pipeline networks.

Status: We have developed a GIS data base showing potential demand for hydrogen, location of existing infrastructure, including current coal-fired power plants and major road and railroads (which are potential rights of way for hydrogen or $\mathrm{CO}_{2}$ pipelines) and possible sites for $\mathrm{CO}_{2}$ sequestration. Preliminary results have been presented at two conferences in 2003. We have not yet estimated costs for alternative pathways for developing fossil hydrogen as an energy carrier, or coordinated with other ongoing GIS based studies of $\mathrm{CO}_{2}$ sequestration potential such as the MIDCARB project.

\section{Schedule for Completing the Work and Deliverables}

Over the year (until August 2004), we plan to complete the three tasks set forth in the original statement of work. In addition, we will use improved understanding from ongoing studies (for example those by the H2A group and the MIDCARB project), to improve our results, especially for Tasks 1 and 3. 


\section{REFERENCES}

W. Amos, "Costs of Transporting and Storing Hydrogen" NREL report No. NREL/TP 570-25106 November 1998.

Benson, H.Y. and Ogden, J.M.: "Mathematical Programming Techniques for Designing Minimum Cost Pipeline Networks for $\mathrm{CO}_{2}$ Sequestration", the Proceedings of the Sixth International Conference on Greenhouse Gas Control Technologies, Kyoto, Japan, 2000.

Bertelè, U. and Brioschi, F.: "Nonserial Dynamic Programming”, Academic Press, New York, 1972.

Carter, R.: "Pipeline Optimization: Dynamic Programming after 30 Years", Technical Report 9803, PSIG, 1998.

Carter, R., Goodreau, M. and Rachford, H.: "Optimizing Pipeline Operations through Mathematical Advances”, Pipeline and Gas Journal, October 2001: 50-51.

Christodoulou, D. "The Technology and Economics of the Transmission of Gaseous Fuels," Master's Thesis, Department of Mechanical and Aerospace Engineering, Princeton University, April 1984.

S. Davis, ORNL Transportation Energy Data Book, Edition 20, October 2000, Table 7.15

Directed Technologies, Inc., Air Products and Chemicals, BOC Gases, The Electrolyser Corp., and Praxair, Inc., 1997: Hydrogen Infrastructure Report, prepared for Ford Motor Company Under USDOE Contract No. DE-AC02-94CE50389, July.

Djebedjian, B., Herrick, A. and Rayan, M.A.: "Modeling and Optimization of Potable Water Network", International Pipeline Conference, ASME, Vol. 2, 2000: 1227-1233.

R. Doctor, et al. "Hydrogen Production and $\mathrm{CO}_{2}$ Recovery, Transport and Use from a KRW Oxygen Blown Gasification Combined Cycle System," Argonne National Laboratory Report, May 1999, Table 7.3

Edgar, T.F.: "Optimal Design of Gas Transmission Networks", Society of Petroleum Engineers Journal, April 1978: 96-104.

Farris, C.B. (1983). "Unusual Design Factors for Supercritical $\mathrm{CO}_{2}$ Pipelines," Energy Progress, 3, 150-158.

Flanigan, O.: "Constrained Derivatives in Natural Gas Pipeline System Optimization", Journal of Petroleum Technology, May 1972:549-556.Foster Wheeler (1998), "Precombustion Decarbonization," Report Number PH2/19, prepared for the IEA Greenhouse Gas R\&D Programme. 
Foster Wheeler (1996): Decarbonization of Fossil Fuels, Report No. PH2/2, prepared for the Executive Committee of the IEA Greenhouse Gas R\&D Programme of the International Energy Agency, March.

Goldberg, D.E. and Kuo C.H.: "Genetic Algorithms in Pipeline Optimization", Journal of Computing in Civil Engineering, 1(2), 1987: 128-141.

Hendriks, C.A. (1994). "Carbon Dioxide Removal from Coal-Fired Power Plants", Ph.D. thesis, Department of Science, Technology, and Society, Utrecht University, Utrecht, The Netherlands.

Hoeven, Tom van der and Gasunie, N. V. Nederlandse: "Some Mathematical Aspects of Gas Network Simulation”, Technical Report 9206, PSIG, 1992.

Holloway, S. (1996) An overview of the Joule II Project. Energy Conversion and Management 37(1-2): 1149-1154.

International Hydrogen Infrastructure Group, private communictions 2003.

Kreutz, T., R. Williams, R. Socolow, P. Chiesa and G. Lozza (2002), “Analysis of Hydrogen and Electricity Production from Fossil Fuels with $\mathrm{CO}_{2}$ Capture," Proceedings of the $6^{\text {th }}$ International Conference on Greenhouse gas Control technologies, 30 Sept-4 October 2002, Kyoto, Japan.

Kreutz, T., Princeton University, Princeton Environmental Institute, private communications, 2002.

Kurani, K, and D. Sperling, 1995.

Larcher, Spitzl, Sekirnjak, Weinberger: "Optimization Problems in the Dispatching of Natural Gas", 12th World Gas Conference of the IGU, Nice 1973.

Larson, R.E. and Wong, P.J.: "Optimization of Natural Gas Systems via Dynamic Programming", Trans. Auto. Cont., IEEE, October 1968, No AC-12: 475-481.

MIDCARB project, http://www.midcarb.org

M. Mintz, S. Folga, J. Gillette, and J. Molburg, "Hydrogen: On the Horizon or Just a Mirage?" Society of Automotive Engineers paper No. 02FCC-155, 2002.

Ogden, J., 1998: Comparison of the Design and Economics of Hydrogen Refueling Station Options, Report to the U.S. Department of Energy under Contract No. DEFG36-95GO10061, December. 
J. Ogden, 1999a, "Strategies For Developing Hydrogen Energy Systems With $\mathrm{CO}_{2}$ Sequestration," Proceedings of the $10^{\text {th }}$ National Hydrogen Association Meeting, Vienna, VA, April 7-9, 1999.

J. Ogden, 1999b, "Developing a Refueling Infrastructure for Hydrogen Vehicles: A Southern California Case Study," International Journal of Hydrogen Energy, vol. 24, pp. 709-730.

Ogden, J. (1999), "Prospects for Building a Hydrogen Energy Infrastructure," Annual Review of Energy and the Environment, 24, 227-279.

Ogden, J. (2003), “Conceptual Design of Optimized Fossil Energy Systems with Capture and Sequestration of Carbon Dioxide," Semi-Annual Technical Progress Report No. 1, to the National Energy Technology Laboratory, USDOE for DOE Award Number: DE-FC26-02NT41623.

J.M. Ogden, E. Kaijuka and W. Wang, "Modeling Fossil Hydrogen Energy Systems with CO2 Sequestration," presented at the $2^{\text {nd }}$ National Carbon Sequestration Meeting, Arlington, VA, May 5-8, 2003.

O’Neill, R.P., Williard, M., Wilkins, B. and Pike R.: “A Mathematical Programming Model for Allocation of Natural Gas", Operations Research, Vol. 27, No. 5, 1978: 857873.

Sekirnjak, E.: "Practical Experiences with Various Optimization Techniques for Gas Transmission and Distribution Systems”, Technical Report 9603, PSIG, 1996.

Smits, A.J.: “A Physical Introduction to Fluid Mechanics”, John Wiley \& Sons, Inc., 1999.

Simbeck, D., 1(999), “A Portfolio Selection Approach for Power Plant $\mathrm{CO}_{2}$ Capture, Separation, and R\&D Options", Proceedings of the Fourth International conference on Carbon Dioxide Removal, Pergamon Press, pp. 119-124.

Skovholt, O. (1993), "CO 2 Transportation System," Energy Conservation and Management, 34(9-11):1095-1103.

Spath, P.L. and W.A. Amos (1999), "Technoeconomic Analysis of Hydrogen Production from Low BTU Western Coal with $\mathrm{CO}_{2}$ Sequestration and Coalbed Methane Recovery Including Delivered $\mathrm{H}_{2}$ Costs," Milestone Report to the US DOE H2 Program.

J. B. Taylor, J.E.A. Alderson, K.M. Kalyanam, A.B. Lyle, and L.A. Phillips, "Technical and Economic Assessment of Methods for the Storage of Large Quantities of Hydrogen,” International Journal of Hydrogen Energy, vol. 11, p. 5, 1986. 
Thomas, C.E., B.D.James, F.D. Lomax, and I.F. Kuhn, (1998). Draft Final Report, Integrated Analysis of Hydrogen Passenger Vehicle Transportation Pathways, report to the National Renewable Energy Laboratory, U.S. Department of Energy, Golden, CO, Under Subcontract No. AXE-6-16685-01, March.

U.S. Energy Information Administration (2001). "Energy Outlook 2002, with Projections Through 2020,” DOE/EIA0383(2002), U.S. Department of Energy, Washington, DC.

White, Curt, National Energy Technology Laboratory, private communications 2003.

Williams, R.H. (1998). "Fuel Decarbonization for Fuel Cell Applications and Sequestration of the Separated $\mathrm{CO}_{2}$," in Eco-restructuring: Implications for Sustainable Development, Ayres (ed.), United Nations Univ. Press, 180-222.

Wolf, Daniel de and Smeers, Yves: "Optimal Dimensioning of Pipe Networks with Application to Gas Transmission Networks", Operation Research, Vol. 44, No. 4, 1996: 596-608.

Wu, S., Rios-Mercado, R. Z., Boyd, E.a. and Scott, L.R.: "Model Relaxations for the Fuel Cost Minimization of Steady-State Gas Pipeline Networks", Mathematical and Computer Modeling, Vol. 31, 2000: 197-220.

Zimmer: "Dynamic Method Models Gas pipeline", The Oil and Gas Journal, 11(1975) 


\section{LIST OF ACRONYMS AND ABBREVIATIONS}

CMI Carbon Mitigation Initiative. Begun in 2001, the Carbon Mitigation Initiative is a ten-year \$15-20 million dollar joint project of Princeton University, BP and Ford Motor Company to find solutions to global warming and climate change.

FCV fuel cell vehicle

GIS geographic information system

GJ $\quad$ gigajoule $\left(=10^{9}\right.$ Joules $)$

SMR steam methane reforming.

USDOE United States Department of Energy Research 
